\title{
AUTOMATED 3D RECONSTRUCTION OF RURAL BUILDINGS FROM STRUCTURE-FROM-MOTION (SFM) PHOTOGRAMMETRY APPROACH
}

\author{
Andrea Pezzuolo, Domenico Giora, Luigi Sartori, Stefano Guercini \\ University of Padova, Italy \\ andrea.pezzuolo@unipd.it
}

\begin{abstract}
Collecting three-dimensional data from indoor and outdoor spaces are prominent for various applications in construction and real estate management. Three-dimensional reconstruction methods for realworld environments based on camera images have recently been studied by many researchers and structure from motion (SFM) has been attracting attention as one of the most practical approaches for 3D reconstruction. Based on photogrammetry, the SfM technique consists in taking photos of the object from all possible angulations and points of view all around the object. In the present work, Structure from Motion is studied and proposed as a low-cost and non-invasive technique for three-dimensional reconstruction of volumes by analysing 6 rural building case studies. Analyses and evaluations of buildings parameters have been made taking advantage of the Agisoft Photoscan software, for reconstruction of three-dimensional volumes from collections of 2-D images. Three-dimensional reconstructions were highly correlated with the manual measurementswith a tape measure considered as references, as demonstrated by high coefficients of determination both for volume $\left(R^{2}\right.$ up to 0.96$)$ and for the wall surface parameter $\left(R^{2}\right.$ up to 0.79$)$.
\end{abstract}

Keywords: rural building, reconstruction, photogrammetry, Structure from Motion.

\section{Introduction}

Collecting spatial data of infrastructures is an almost everyday task in the engineering and construction sector [1]. However, data from internal and external spaces (i.e., shape, size, position, and orientation) are prominent for various applications in rural buildings and consequent management [2].

Nowadays this task is primarily carried out with three approaches: tape measure, laser scanning, and image-based 3D reconstruction [3; 4].Manual measurement with a tape measure is the easiest method that needs no expertise, but it is expensive in terms of time, labor and not always accurate [5].Laser scanners create a point cloud of a target object [6]. The time spent to collect 3D coordinates of a point is very low (compared to tape measuring), while the accuracy of the data points is high, however, the limiting factor for use of this system is high equipment costs[7]. Finally, it is imagebased 3D reconstruction from image conversion of a corresponding "image points" into a cloud of 3D points [8]. This approach is inexpensive once the initial investment in camera equipment has been made, however, the generated point could be noisy depending on the visual properties or complexity of the scene [9].

In the last years, optical systems are often used for agricultural [10-12] and livestock [13; 14] applications, in particular, three-dimensional reconstruction methods based on camera images have been studied by many researchers $[15 ; 16]$ and structure from motion (SfM) has been attracting attention as one of the most practical approaches for 3D reconstruction. Based on photogrammetry (a novel branch of topography), the SfM technique consists in taking photos of the object from all possible angulations and points of view all around the object [17]. Several studies had used this technique in order to collect data about plant phenology [18], livestock applications [19], soil topography and roughness [20], but the SfM technique could be also implemented for indoor and outdoor reconstructions in rural buildings.

In the present work, the SfM technique is studied and proposed as a low-cost and non-invasive technique for three-dimensional reconstruction of volumes by analyzing some rural building case studies. Analyzes and evaluations of volumetric parameters have been made taking advantage of the Agisoft Photoscan software, for reconstruction of three-dimensional volumes from collections of 2D images.

In order to verify the modelling process validity, a set of comparisons has been scheduled considering the reference manual measurements. For the scope, building parameters (volume and wall surface)were defined and estimated both from the 3D digital model and from the reference manual measurements with a tape measure. Moreover, measurement and processing times have been considered for both systems. 


\section{Materials and methods}

\section{Case studies}

For the present study, 6-rural buildingswith different shape, volume and area were analysed (Table 1). In particular:

- farm equipment shedbuilt fromprefabricatedmaterials (4);

- point of sale in a farm wine cellar;

- ruined farmhouse building.

A commercial camera was implemented for collection of images needed in rural buildings SfM reconstruction. Specifically, a Nikon D5100 camera was used, featuring a 23.6×15.6 mm CMOS sensor with a $4928 \times 3264$ pixels' resolution and a lens with a $35 \mathrm{~mm}$ focal length. Frameswere captured taking advantage of both natural (outdoor spaces) and artificial light (indoor spaces). Distances from the target and overlapping percentages were different depending on the complexity and dimensions of the reconstructed surfaces, while the relative angle was always kept within $\pm 15^{\circ}$ from the orthogonality to the imaged surface. In all of the cases, images were taken in a time lower than 5 minutes, in order to minimize distortions ascribable to the sun light intensity and position variations. Diffused daylight was estimated to have a 250-350 lux illuminance in the proximity of the subject.

Table 1

Frame properties related to the 6 monitored rural buildings

\begin{tabular}{|c|c|c|c|c|c|}
\hline ID & Building & Spaces & $\begin{array}{c}\text { Number of } \\
\text { frames }\end{array}$ & $\begin{array}{c}\text { Distance to the } \\
\text { building, m }\end{array}$ & $\begin{array}{c}\text { Average } \\
\text { overlapping, \% }\end{array}$ \\
\hline 1 & Farm equipment shed 1 & Outdoor & 70 & $2-10$ & $30-60$ \\
\hline 2 & Farm equipment shed 2 & Outdoor & 80 & $2-10$ & $30-60$ \\
\hline 3 & Farm equipment shed 3 & Outdoor & 105 & $2-10$ & $35-70$ \\
\hline 4 & Farm equipment shed 4 & Outdoor & 125 & $2-10$ & $35-70$ \\
\hline 5 & Farm wine cellar & Indoor & 130 & $1-5$ & $50-80$ \\
\hline 6 & Ruined farmhouse & Indoor & 125 & $4-20$ & $30-60$ \\
\hline
\end{tabular}
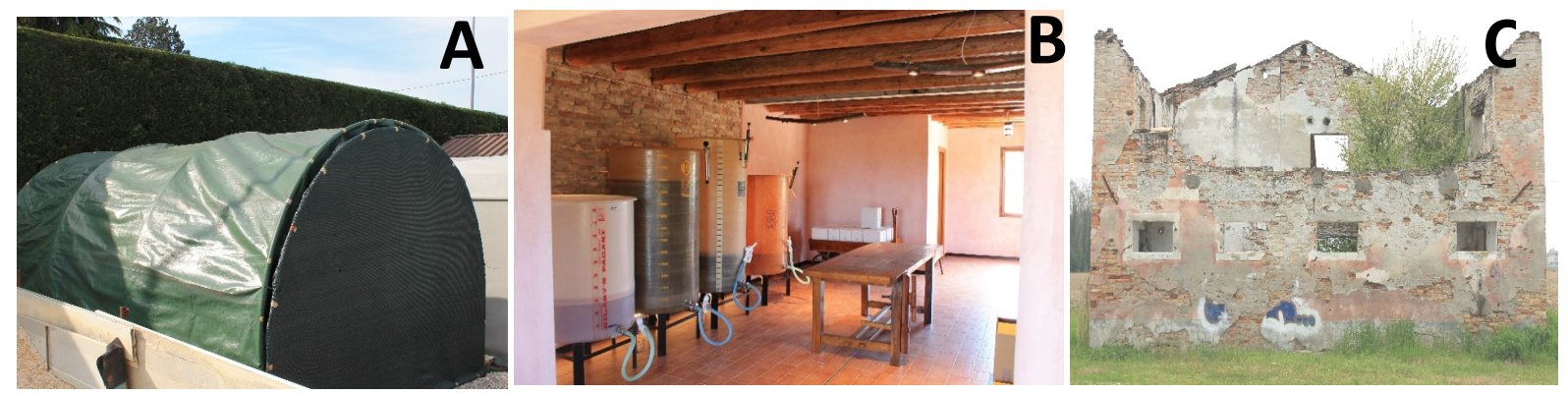

Fig. 1. Farm equipment shed (A), point of sale in farm wine cellar (B) and ruined farmhouse building $(\mathbf{C})$

\section{Structure from motion and data processing}

Structure-from-Motion is a photogrammetry method based on the estimation of the motions of a camera to allow reconstruction of three-dimensional point clouds(Fig. 2) through a few differentsteps. Firstly, the images are segmented in order to eliminate external elements, which could disturb or distort the 3D reconstruction process; then features are identified in the scene and used to find matching between the image pairs. Robust pairwise geometry is then estimated andused to produce a $3 \mathrm{D}$ point triangulation and transformation of the relative camera poses to a common coordinate frame.

Three-dimensional reconstructionwas carried out through AgiSoft PhotoScan software (version 1.3.1) allowing reconstruction of three-dimensional point clouds through the SfM approach (Fig. 3). The measurement process was carried out through two different methods:

- semi-automatic approach, with extraction of reference point coordinates from the threedimensional model and quantification of volumes and areas starting from the relative distances of such reference positions; 
- automatic approach, with estimation of the reference area and volume parameters directly performed by implemented software in a totally automatic way or just handling surfaces closure.

The reconstruction process and the extraction of the parameters were repeated three times, in order to verify the variability of the process. AgiSoft PhotoScan was chosen because of the affordable cost, practical user interface, capability to intrinsically determine the camera parameters and perform calibration, local processing, and extremely detailed high-resolution 3D models.

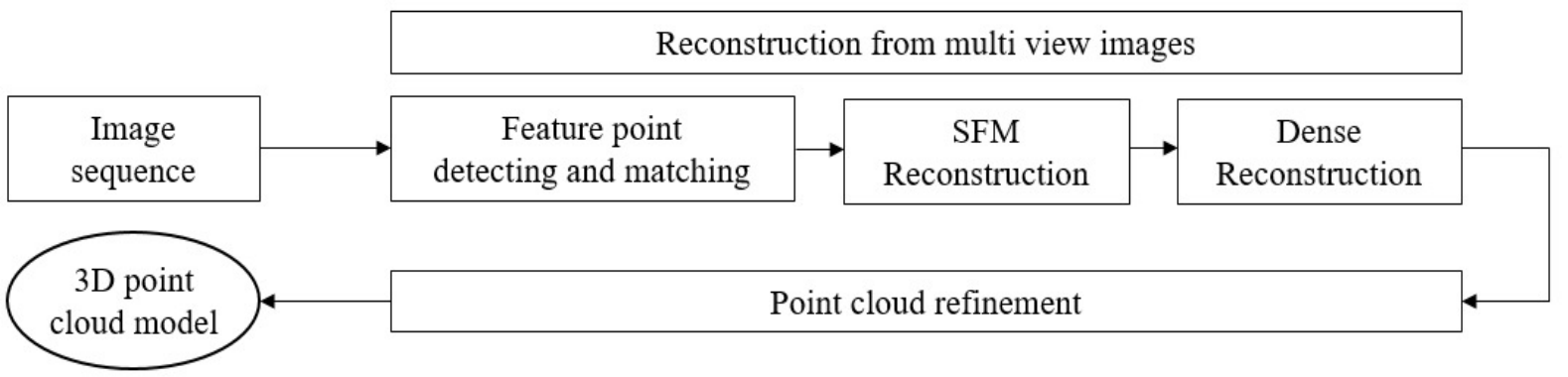

Fig. 2. Schematic process for image-based 3D point cloud generation
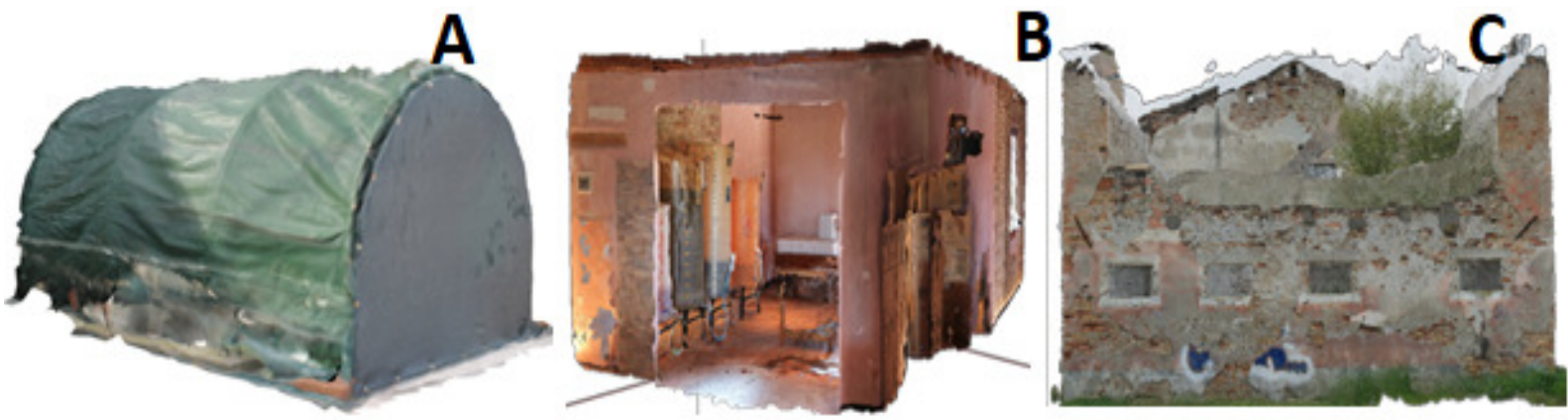

Fig. 3. Example of frame collection processrespectively for farm equipment shed (A), point of sale in farm wine cellar (B) and ruined farmhouse building $(C)$

\section{Results and discussion}

\section{$3 D$ reconstruction quality}

The quality of the reconstruction process was firstly analysed quantifying the percentage of the reconstructed surface as a function of the number of frames provided to the software routine in a reference structure (Fig. 4).
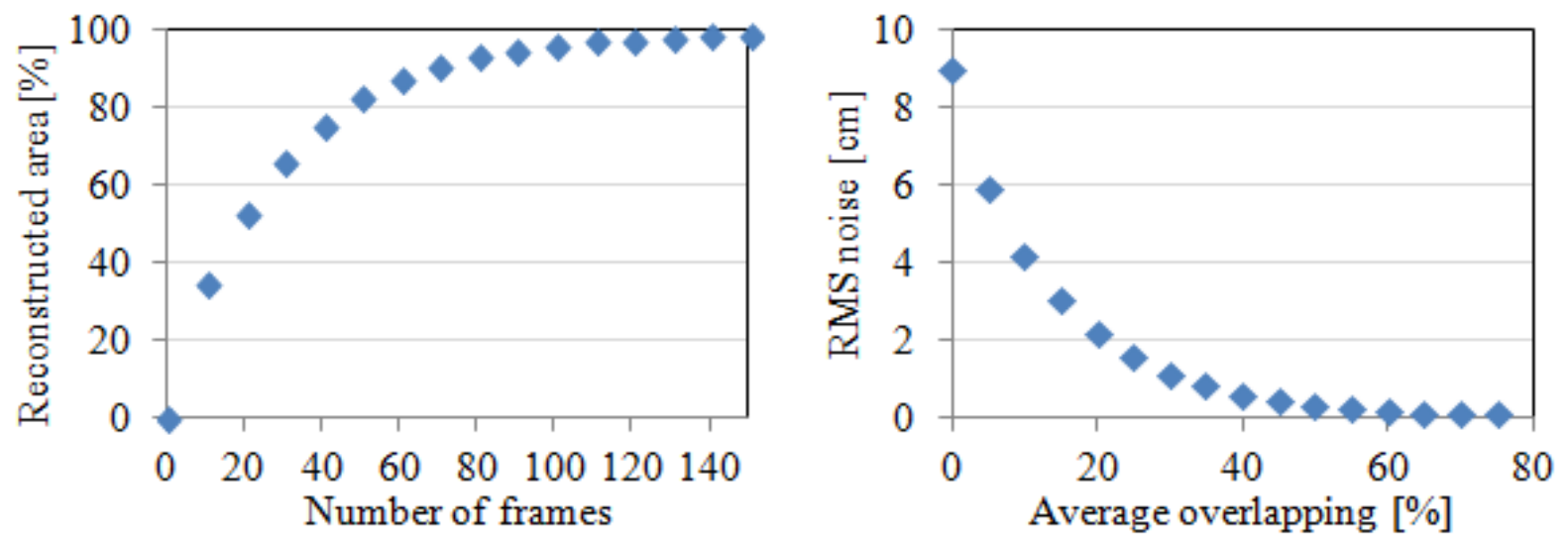

Fig. 4.Reconstruction quality in terms of area and RMS noise

Concurrently the average noise, expressed in terms of root mean square (RMS) deviations from the main surface, was also computed and reported as a function of the average overlapping between adjacent images (Fig. 4). It can be noticed how a minimum of 50 frames is sufficient to achieve a 
reconstruction of over $80 \%$ of the total area of the reference structure, while 70 frames (here used as the minimum standard) allow a reconstruction of more than $90 \%$ of the area. The higher is the number of frames, the higher the overlapping and the lower the noise affecting the reconstructed surfaces. As it can be noticed by the reported results (Fig. 4), having considered a minimum overlapping of $30 \%$ allowed RMS noise to be kept always below $2 \mathrm{~cm}$.

\section{Estimated building parameters}

Results of the comparison against the manual approach are reported in Table 2. Threedimensional reconstruction developed on the basis of markers positioned in reference points on the volume of interest present a high correlation.

In the case of semi-automatic reconstruction, the determination index $\left(R^{2}\right)$ estimated vs manual measurements isequal to 0.99 with a slight underestimation of about $1 \%$ of the software analysis with respect to the manually estimated volume.The reasons for this underestimation are likely to be sought for a suspected calibration error of the 3D model or for an error in the location of the markers.

Automating the operation of 3D reconstruction (automatic measurement), the determination index is slightly lower (equal to 0.96) and with a deviation, which, nevertheless, does not increase significantly by 0.988 (underestimation of about $1.2 \%$ ).

Table 2

Manual vs automatic measurement: comparison of estimated volume and wall surface

\begin{tabular}{|c|c|c|c|c|c|c|}
\hline \multirow{2}{*}{ ID } & \multicolumn{3}{|c|}{ Volume (standard deviation), $\mathbf{~ m}^{\mathbf{3}}$} & \multicolumn{3}{c|}{ Wall surface (standard deviation), $\mathbf{~}^{\mathbf{2}}$} \\
\cline { 2 - 7 } & Manual & Semi-automatic & Automatic & Manual & Semi-automatic & Automatic \\
\hline 1 & $24.34(1.51)$ & $24.61(1.13)$ & $16.62(0.48)$ & $18.12(1.04)$ & $18.23(0.98)$ & $55.43(1.54)$ \\
\hline 2 & $29.16(1.72)$ & $26.88(1.24)$ & $27.95(0.88)$ & $46.98(2.66)$ & $46.78(2.23)$ & $68.90(2.23)$ \\
\hline 3 & $65.25(3.76)$ & $64.93(3.27)$ & $24.60(0.71)$ & $93.68(5.38)$ & $99.78(4.72)$ & $128.0(3.66)$ \\
\hline 4 & $118.9(6.76)$ & $116.30(5.26)$ & $74.40(2.05)$ & $123.9(7.31)$ & $122.1(6.29)$ & $196.0(5.91)$ \\
\hline 5 & $89.38(5.86)$ & $86.32(4.47)$ & $80.89(2.44)$ & $60.66(3.49)$ & $59.44(2.97)$ & $166.5(5.26)$ \\
\hline 6 & $411.5(22.2)$ & $408.4(21.1)$ & $427.5(12.9)$ & $143.3(8.02)$ & $145.8(6.92)$ & $310.6(8.75)$ \\
\hline
\end{tabular}

Regarding the measurements on the wall surface (Tab. 2), the semi-automatic approachexhibited a high correlation (index of determination $\mathrm{R}^{2}=0.997$ )with an average overestimation of $1.2 \%$. Such correspondence also demonstrates the appropriateness of the procedure for estimating not only volumes, but also surfaces.

With a totally automated approach, an acceptable correlation was also obtained $\left(R^{2}=0.797\right)$. However, there is an overestimation by the software of about $88 \%$. This overestimation is due to two important factors: during the calculation phase, not only the areas of flat surfaces, but also the areas of all the objects present in the model are considered (e.g., beams, columns or nonlinear rectilinear trends), creating linear deviations that tend to increase the presently estimated area. Moreover, the surface is overestimated, because the software also considers "closing areas" that close openings between the various areas in the model.

\section{Measurement and processing time}

The results of the comparison on measuring and processing time are reported in Table 3 .

Table 3

Measurement and processing time: comparison of manual vs automatic measurement

\begin{tabular}{|c|c|c|c|}
\hline \multirow{2}{*}{ ID } & \multicolumn{3}{|c|}{ Measurement and processing time (standard deviations), $\mathbf{h}$} \\
\cline { 2 - 4 } & Manual & Semi-automatic & Automatic \\
\hline 1 & $0.50(0.03)$ & $0.42(0.03)$ & $0.33(0.02)$ \\
\hline 2 & $0.50(0.03)$ & $0.42(0.03)$ & $0.33(0.02)$ \\
\hline 3 & $0.67(0.03)$ & $0.42(0.03)$ & $0.25(0.02)$ \\
\hline 4 & $0.58(0.03)$ & $0.33(0.02)$ & $0.25(0.02)$ \\
\hline 5 & $0.75(0.04)$ & $0.58(0.04)$ & $0.42(0.03)$ \\
\hline 6 & $1.75(0.06)$ & $0.75(0.05)$ & $0.42(0.03)$ \\
\hline
\end{tabular}


With regard to such analysis, both automatic and semi-automatic approaches highlighted a clear reduction of the needed time, with evident cost-saving benefits associated to their application. More specifically, compared to the manual measurements, reductions in time that can reach 40-50\% and 50$70 \%$ respectively in the case of semi-automatic and automatic approaches. It is worth noting that differently from volume and area measurements, not high correlations could be identified between manual and automatic or semi-automatic measurements. This is most probably due to the fact that manual processing times depend on a variable way on the complexity of the analysed building rather than on its dimensions.

\section{Conclusions}

In the present paper Structure-from-Motion ( $\mathrm{SfM}$ ) is studied and proposed as a low-cost and noninvasive technique for three-dimensional reconstruction of rural buildings.

1. Analyses carried out on 6 buildings models clearly show how SfM has the potential to provide a three-dimensional reconstruction, which can be applied for quantitative extraction of the building parameters.

2. Three-dimensional reconstruction developed on the basis of markers positioned in reference points on the volume of interest present a high correlation both for the volume $\left(R^{2}=0.99\right)$ and for the surface $\left(R^{2}=0.99\right)$. With a completely automated approachthe determination index is slightly lower both for the volume $\left(R^{2}=0.96\right)$ and for the surface $\left(R^{2}=0.79\right)$ due to overestimation of the area.

3. In term of time, there was no direct proportionality between the manual and automatic measurement. This is due to the fact that manual processing times depend in a variable way on the complexity of the analysed building rather than on its dimensions. However, it is possible to reduce the measurement and processing time.

4. Measuring volumes or areas can be useful, when it is necessary to know the air flow rates, or it is necessary to carry out surface treatment or coating operations, or where you want to know the effective air exchange with the outside.

\section{Acknowledgements}

The authors wish to thank Dr. Christian De Biasi for his technical support and execution of manual measurements.

\section{References}

[1] Fathi H., Dai F., Lourakis M., Automated as-built 3D reconstruction of civil infrastructure using computer vision: Achievements, opportunities, and challenges. Advanced Engineering Informatics, vol. 29(2), 2015, pp. 149-161.

[2] Vázquez-Arellano M., Griepentrog H.W., Reiser D., Paraforos D.S., 3-D imaging systems for agricultural applications - a review. Sensors, vol. 16, 2016, pp. 618-626.

[3] Dai F.,Lu M. Assessing the accuracy of applying photogrammetry to take geometric measurements on building products. J. Construct. Eng. Manage. vol. 136(2), 2010, pp. 242-250.

[4] Zhu Z., Brilakis I., Comparison of optical sensor-based spatial data collection techniques for civil infrastructure modeling. J. Comput. Civil Eng. vol. 23(3), 2009, pp. 170-177.

[5] Pezzuolo A., Guarino M., Sartori L., Marinello F., A feasibility study on the use of a structured light depth-camera for three-dimensional body measurements of dairy cows in free-stall barns. Sensors (Basel, Switzerland), vol. 18, 2018, pp. 673.

[6] Golparvar-Fard M., Bohn J., Teizer J., Savarese S., Peña-Mora F. Evaluation of image-based modeling and laser scanning accuracy for emerging automated performance monitoring techniques. Autom. Construct. vol. 20(8), 2011, pp. 1143-1155.

[7] Dubbini M., Pezzuolo A., De Giglio M., Gattelli M., Curzio L., Covi D., Yezekyan T., Marinello F., Last generation instrument for agriculture multispectral data collection. CIGR Journal, vol. 19, 2017, pp. 158-163.

[8] Bhatla A., Choe S., Fierro O., Leite F., Evaluation of accuracy of as-built 3D modeling from photos taken by handheld digital cameras. Autom. Construct. vol. 28, 2012, pp. 116-127. 
[9] Marinello F., Schiavuta P., Cavalli R., Pezzuolo A., Carmignato S., Savio E., Critical factors in cantilever near-field scanning optical microscopy. IEEE Sensors Journal, vol. 14/9, 2014, pp. 3236-3244.

[10] Marinello F., Pezzuolo A., Gasparini F., Sartori L., Three-dimensional sensor for dynamic characterization of soil microrelief. In Precision Agriculture 2013 - Papers Presented at the 9th European Conference on Precision Agriculture, ECPA 2013, pp. 71-78.

[11] Pezzuolo A., Dumont B., Sartori L., Marinello F., De Antoni Migliorati M., Basso B. Evaluating the impact of soil conservation measures on soil organic carbon at the farm scale. Comput. Electron. Agric vol. 135, 2017, pp. 175-182.

[12] Boscaro D., Pezzuolo A., Sartori L., Marinello F., Mattioli M., Bolzonella D., Grigolato S. Evaluation of the energy and greenhouse gases impacts of grass harvested on riverbanks for feeding anaerobic digestion plants. Journal of cleaner production, vol. 172, 2018, pp. 4099-4109.

[13] Pezzuolo A., Guarino M., Sartori L., González L.A., Marinello F., On-barn pig weight estimation based on body measurement by means of a Kinect v1 sensor. Comput. Electron. Agric., vol. 148, 2018, 29-36.

[14] Da Borso F., Chiumenti A., Sigura M., Pezzuolo A. Influence of automatic feeding systems on design and management of dairy farms. Journal of Agricultural Engineering, vol. 48, 2017, pp. 48-52.

[15] Marinello F., Proto A.R., Zimbalatti G., Pezzuolo A., Cavalli R., Grigolato S., Determination of forest road surface roughness by Kinect depth imaging. Ann. For Res., vol. 60, 2017, pp. 1-10.

[16] Cillis D., Pezzuolo A., Marinello F., Sartori L., Field-scale electrical resistivity profiling mapping for delineating soil condition in a nitrate vulnerable zone. Applied Soil Ecology., 2017, In press.

[17] Westoby M.J., Brasington J., Glasser N.F., Hambrey M.J., Reynolds J.M., Structure-from-motion photogrammetry: A low-cost, effective tool for geoscience applications. Geomorphology, vol. 179, 2012, pp. 300-314.

[18] Jay S., Rabatel G., Hadoux X., Gorretta N., In-field crop row phenotyping from 3d modeling performed using structure from motion. Comput. Electron. Agric., vol. 110, 2015, pp. 70-77.

[19] Pezzuolo A., Gonzàlez L.A., Giora, D., Sartori L., Cillis D., Marinello F., Body measurements of dairy cows using a structure from motion (SfM) photogrammetry approach. In Proceedings of the 8th European Conference on Precision Livestock Farming, Nantes, France, 2017.

[20] Javernick L., Brasington J., Caruso B., Modelling the topography of shallow braided rivers using Structure-from-Motion photogrammetry. Geomorphology, vol. 213, 2014, pp. 166-182. 